IMPACT OF USING NEW COMMERCIAL GLUTATHIONE ENRICHED INACTIVE DRY YEAST OENOLOGICAL PREPARATIONS ON THE AROMA AND SENSORY PROPERTIES OF WINES

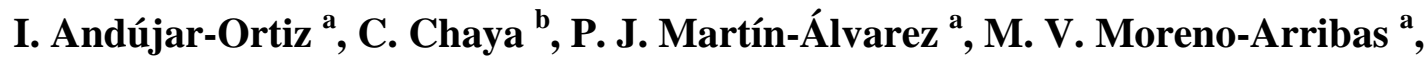 \\ M.A. Pozo-Bayón ${ }^{\text {a }}$

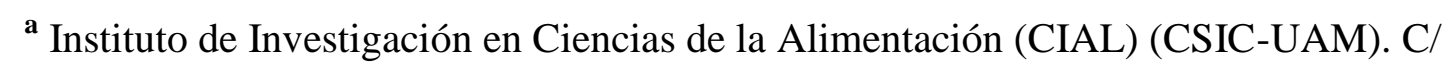 \\ Nicolás Cabrera, 9, Campus de la Universidad Autónoma de Madrid, Cantoblanco, \\ 28049 Madrid, Spain.

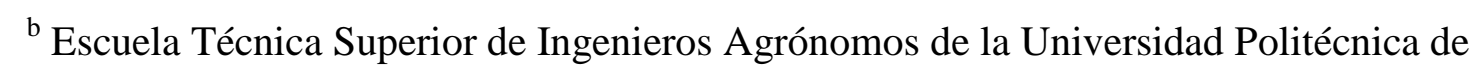 \\ Madrid, Ciudad Universitaria s/n, 28040 Madrid, Spain
}

14

Running title: Glutathione inactive dry yeast preparations in wines

\title{
ABSTRACT
}

The effect of the addition of a commercial enriched glutathione Inactive Dry Yeast (GSH-IDY) oenological preparation in the volatile and sensory properties of industrially manufactured rosé Grenache wines was evaluated during their shelf-life. In addition, triangle tests were performed at different times during wine aging (among 1 and 9 months) to determine the sensory differences between wines with and without GSH* corresponding author: mdelpozo@ifi.csic.es phone: + 34910017900 ext: 961 
25 IDY preparations. Descriptive sensory analysis with a trained panel was carried out

26 when sensory differences in the triangle test were noticed. In addition, consumer tests

27 were performed in order to investigate consumers' acceptability of wines. Results

28 revealed significant sensory differences between control and GSH-IDY wines after 9

29 months of aging. At that time, GSH-IDY wines were more intense in fruity aromas

30 (strawberry, banana) and less intense in yeast notes than control wine. The impact of

31 the GSH-IDY in the aroma might be the consequence of different effects that these

32 preparations could induce in wine composition: modification of yeast byoproducts

33 during fermentation, release of volatile compounds from IDY, interaction of wine

34 volatile compounds with yeast macromolecules from IDY and a possible antioxidant

35 effect of the glutathione released by the IDY preparation on some specific volatile

36 compounds.

37

38 Key words: Wine, Glutathione, Inactive Dry Yeast Preparations, aroma, sensory analysis 
42 Oxidation processes constitute a serious problem during winemaking and especially in the case of young wines. In general terms, oxidation of young wines, is associated with a rapid loss of the pleasant sensory characteristics of wine, particularly affecting the floral and fruity notes, and the formation of unpleasant new aromas of typical aged wine, as well as atypical aromas associated with wine spoilage ${ }^{[1-3]}$. Wine oxidation also produces wine browning, which results from the oxidation of phenols to quinones, which in turn polymerise to form macromolecules with a typical yellow-brown hue ${ }^{[4] .}$ The exogenous addition of $\gamma$-L-glutamyl-L-cysteinylglycine, named as glutathione 50 (GSH), a tripeptide of non-proteic origin of known antioxidant properties ${ }^{[5]}$, is now 51 being studied by the OIV (International Organisation of Vine and Wine) since it has 52 been shown that it prevents the enzymatic browning of white wines ${ }^{[6,7]}$, and also preserves varietal aroma compounds, reducing the occurrence of aged off-flavor

54 compounds ${ }^{[5]}$. However, the use of this compound during winemaking is not allowed so 55 far.

57 In contrast, from the different types of Inactive Dry Yeast (IDY) preparations allowed 58 for different applications during winemaking ${ }^{[8]}$, some of them are claimed to prevent 59 wine oxidation because of their higher content in GSH. Recently, new research 60 performed in our laboratory, has shown a higher level of GSH released into synthetic 61 wines by GSH enriched IDY preparations (GSH-IDY) compared to other non-GSH IDY 62 preparations ${ }^{[9]}$. In addition, it has been shown that these preparations might reduce 63 terpene oxidation in synthetic wines submitted to accelerated aging conditions ${ }^{[10]}$. 64 Nevertheless, the impact of glutathione enriched IDY preparations to preserve and/or to 
65 improve the sensory characteristics of wines industrially manufactured has not been

66 studied so far. Only the effect of the addition of an IDY preparation in the overall

67 sensory perception of finished wines and their impact on the mouthfeel and taste

68 properties have been studied ${ }^{[11,12]}$ Keeping these antecedents in mind and taking into

69 consideration the importance of contributing to a better knowledge in the use of these

70 preparations during winemaking, the objective of the present research was to evaluate

71 the effect of a glutathione enriched commercial IDY preparation (GSH-IDY) on the volatile and sensory properties of an industrially manufactured rosé Grenache wine during its shelf-life.

MATERIAL AND METHODS

Description of the wines

Two different types of monovarietal Grenache rosé wines from the 2008 vintage, a 80 control wine and a GSH-IDY wine, were industrially manufactured in a winery from the 81 O.D. Navarra, Spain. To do so, 10,000 L tanks were filled with the same must. GSH-

82 IDY wine was prepared by adding the advised dosage $\left(20 \mathrm{~g} \mathrm{HL}^{-1}\right)$ of a commercial 83 glutathione enriched IDY preparation from a yeast autolysate (Saccharomyces 84 cerevisiae) specially recommended by the manufacturers to prevent wine aroma 85 oxidation. A control wine was also made from the same must without GSH-IDY 86 addition. To carry out the alcoholic fermentation, the same active dry yeast was 87 inoculated in both types of wines. All the wines were stabilised and clarified in the 88 winery, and sent to our laboratory for the instrumental and sensory analysis. Wines were 89 kept at $12{ }^{\circ} \mathrm{C}$ during 10 months. 
90 General parameters during winemaking (probable alcohol degree in musts, total acidity,

91 volatile acidity and alcohol degree in wines) were determined according to the official

92 methods of wine analysis ${ }^{[13]}$. From these determinations, it can be concluded that

93 fermentation performance was similar in both types of wines and finished wines had

94 values considered in the normal range for this type of wines (Table 1).

95

96 Volatile compounds

97

To determine the effect of GSH-IDY on the volatile profile and its evolution over time,

99 wine volatiles were analyzed after 1, 2, 3 and 9 months of wine aging. To do so, $8 \mathrm{~mL}$

100 of wine spiked with $50 \mu \mathrm{L}$ of a solution of methyl nonanoate $\left(5 \mathrm{mg} \mathrm{L}^{-1}\right)$ used as internal

101 standard were placed in a $20 \mathrm{~mL}$ headspace vial and sealed with a PTFE/Silicone

102 septum (Supelco, Bellefonte, PA). Vials were kept at $40{ }^{\circ} \mathrm{C}$ for $10 \mathrm{~min}$ to reach

103 equilibrium before the extraction. The extraction was performed during 20 minutes at

$10440{ }^{\circ} \mathrm{C}$ under constant stirring (500 rpm), using a StableFlex $85 \mu \mathrm{m}$ carboxen-

105 polydimethylsiloxane, CAR-PDMS fibre (Supelco). The same fibre was used

106 throughout the study and its performance was periodically checked. After the extraction,

107 the fibre was removed from the sample vial and desorbed in the GC injector port in

108 splitless mode for $10 \mathrm{~min}$. An Agilent 6890N GC system (Agilent, Palo Alto, CA) with

109 a split/splitless injector and interfaced with an Agilent 5973 mass spectrometer was

110 used for sample analysis. The injector was set at $280^{\circ} \mathrm{C}$. An Agilent MSD ChemStation

111 Software (D.01.02 16 version) was used to control the system. Separation was

112 performed on a Carbowax $10 \mathrm{M}$ column $(30 \mathrm{~m} \times 0.25 \mathrm{~mm}$ i.d. $\mathrm{x} 0.5 \mu \mathrm{m})$. The oven

113 temperature was programmed as follows: $40{ }^{\circ} \mathrm{C}$ as initial temperature, held for 5

114 minutes. In a first ramp the temperature increased to $60{ }^{\circ} \mathrm{C}$ at $1{ }^{\circ} \mathrm{C} \min ^{-1}$ and, in the 
115 second, to $160{ }^{\circ} \mathrm{C}$ at $5^{\circ} \mathrm{C} \mathrm{min}{ }^{-1}$, then held for 1 minute. In a third ramp the temperature

116 increased to $180^{\circ} \mathrm{C}$ at $20^{\circ} \mathrm{C} \mathrm{min}{ }^{-1}$, then held for 2 minutes. Helium was the carrier gas

117 (7 psi and $\left.1 \mathrm{~mL} \mathrm{~min}^{-1}\right)$. For the MS system, the temperatures of the manifold and transfer

118 line were 150 and $230^{\circ} \mathrm{C}$ respectively; electron impact mass spectra were recorded at 70

$119 \mathrm{eV}$ ionization voltages and the ionization current was $10 \mu \mathrm{A}$. The acquisitions were

120 performed in scan mode (from 35 to $450 \mathrm{~m} / \mathrm{z}$ ). Analyses were made in duplicate. The

121 identification was carried out by comparison of the mass spectra of the peaks in the

122 samples with those reported in the mass spectrum libraries, and using the reference

123 compounds when possible. Moreover, linear retention indexes were experimentally

124 calculated with an n-alkane mixture (C5-C30) and compared with those available in the

125 literature. For quantification purposes, the relative area was obtained as the TIC signal

126 of each aroma compound divided by the area of the internal standard. For those

127 compounds whose standards were available, calibration curves in synthetic wines with

128 each of the reference compounds (5 levels of concentration $\times 2$ repetitions) were used,

129 after checking the absence of significant matrix effects for most of the volatile analyzed

130 by the comparison of the slopes of the regression curves obtained in the synthetic and

131 real wines following the same methodology described by Rodriguez-Bencomo and

132 collaborators ${ }^{[14]}$. A Semiquantification, considering that the response factor of the

133 compound had the same value that the internal standard, was carried out when the

134 reference standards were not available.

135

136 Triangle tests during the shelf-life of the wines

138 Triangle tests were carried out by a panel of 12 judges ( 6 men, 6 women, aged from 28

139 to 68) belonging to the staff of the Technical University of Madrid. They were 
140 previously trained in detection and recognition of tastes and odours, in the use of scales

141 and in difference and ranking assessments according to the International Organization for Standardization ISO 8586-1 [15].

144 Three wine samples were presented to the judges identified by three-digit random

145 codes. The order of presentation was randomly assigned for each judge, verifying that

146 for the whole panel, presentation order of the samples was balanced. Wine $(25 \mathrm{~mL})$ was

147 served in tulip-shaped ISO tasting glasses at a constant temperature of $12{ }^{\circ} \mathrm{C}$, and

148 covered with plastic Petri dishes to allow the volatiles to equilibrate in the headspace.

149 Tests were performed in a sensory lab provided with 16 individual booths and

150 complying with usual requirements such as proper light and temperature control and

151 isolation from noises and odours. No information about the aim of the study or about

152 wine samples was given to the judges prior to the tests. Judges were asked to evaluate

153 samples from left to right, looking for differences in aroma and taste. Judges were

154 informed that two samples were identical and one sample was different. They had to

155 select the odd sample. Judges rested between samples, rinsed their mouth with water

156 and ate breadsticks when necessary. Triangle tests were performed throughout the shelf-

157 life of wines, specifically, after 1, 2, 3 and 9 months of wine aging. Judges were given

158 rewards and provided with positive feed back, as motivated judges are more focused

159 and have better performance.

160

\section{Descriptive analysis}

163 The panel was composed by 3 men and 7 women aged from 24 to 68 , belonging to the

164 Technical University of Madrid. All conditions were identical to those described before. 
165 Descriptive analysis of the two types of rosé wines was carried out in three 2 -h sessions

166 divided in training, training evaluation and wine evaluation.

167

168 Training. In the first training session, 12 representative attributes of Grenache wines 169 were prepared at the highest concentration described in Table 2 and presented to the 170 judges. During this first training session, judges were first asked to smell the standards 171 corresponding to the 12 attributes to familiarize themselves, and then, they were asked 172 to rate the intensity of the wines for each attribute in an unstructured $15 \mathrm{~cm}$ line scale 173 anchored at $1.5 \mathrm{~cm}$ from the end points of the line with the words "low" and "high". In 174 this step, judges were introduced to the score card, the rating scale and procedure 175 protocol of evaluation. This training period allowed choosing the attributes most 176 representatives in both wines. At the conclusion of the first training period, 6 attributes were selected (strawberry, peach, banana, floral, yeast, acidity) (Table 2). The second and third sessions were focused on refining the standards and training the judges in using the terms consistently. To do so, aromas were presented at random at low and/or

180 high concentration (Table 2), together with a form containing an unstructured $15 \mathrm{~cm}$

181 line scale as described before where the corresponding intensity was rated.

183 Training evaluation. Booths with 2 wine tasting glasses containing each of the 6 184 standard references at two concentrations (low and high) were prepared as explained 185 before, and properly coded and covered with aluminium paper to avoid the influence of 186 sample colour in the wine tasting evaluation. Judges were asked to determine the 187 attribute and to rate the intensity of the standard in the same unstructured $15 \mathrm{~cm}$ line 188 scale as described before. Training evaluation was done in duplicate, therefore each 189 judge rated the 6 attributes at two concentrations twice, with the exception for acidity, 
190 for which judges had been previously trained for different sensory studies. Statistical

191 evaluation of performance of the panel was done by two-way ANOVA, in order to 192 discard attributes scores from judges not consistent with the whole panel for the 193 subsequent sessions.

195 Wine evaluation. Wine evaluation was carried out after training and training evaluation.

196 Both wines were identified by three digit random codes and the presentation order of 197 the samples was randomly assigned and balanced for the whole panel. Judges rated each

198 of the 6 attributes using the same unstructured $15 \mathrm{~cm}$ line explained before. First, they 199 were asked to rate the intensity of each aroma attribute in both wines by the orthonasal 200 way. Finally, they were asked to taste the wine and to rate the acidity for both wines.

\section{Consumer tests}

204 Hedonic evaluation of both types of wines (control wine and GSH-IDY wine) were 205 investigated by a panel of consumers $(n=64)$ belonging to the staff of our research 206 institution (CIAL). The selection criteria were focused on consumers who generally 207 enjoy rosé wines, with no ethical or medical reasons for not consuming alcohol. For this 208 study consumers were recruited taking into consideration a balanced distribution by sex 209 (56\% male and 44\% women). In addition most of them were aged from $21-34$ (56\%), 210 while consumers aged from 35-49, 50-65 and older than 65 years old represented the 21120,17 and 6\%, respectively. No specific information about the samples was given to 212 consumers prior the study. As described before, samples were identified by three-digit 213 random codes at constant serving temperature, using a randomised and balanced serving 214 order across consumers. Consumers were asked to rate each wine for overall liking on a 
2159 point hedonic scale from "dislike extremely" to "like extremely". Paper score-sheets

216 were used for data collection.

217

\section{Statistical analysis}

219

220 Results corresponding to the concentration of volatile compounds in both types of wines

221 throughout wine shelf-life were submitted to cluster analysis to provide a general view

222 of the main factors involved on data variation (addition of GSH-IDY and aging time). In

223 addition, one-way ANOVA was made to test the effect of aging time in each type of

224 wine. Triangle tests results were analysed as described in ISO $4120^{\text {[16]. }}$ Data from the

225 training evaluation for each sensory attribute were submitted to two-way ANOVA to

226 determine the effect of the two studied factors (concentration and judges). Consistency

227 of scores among judges was assessed by the interaction concentration $\mathrm{x}$ judge in order

228 to guarantee that each attribute was perceived by the whole panel similarly. Data from

229 the wine evaluation were submitted to one way ANOVA, using the t-test when

230 differences in both wines were found. Data from the consumer tests were analysed by a

231 mixed model, considering wines as fixed effect and consumers as random effect ${ }^{[17]}$.

232 STATISTICA 7.1 (www.statsoft.com) and STATGRAPHICS Plus 5.0

233 (www.statgraphics.com) were used for data processing.

234

235 RESULTS AND DISCUSSION

236

237 Evolution of the volatile profile during the shelf-life of the wines

238 
239 To determine the effect of the IDY-preparation on the volatile profile of the wines, we

240 focused on the evolution of a wide range of volatile compounds (Table 3) belonging to

241 different chemical classes: esters (ethyl esters of fatty acids and higher alcohol acetates),

242 alcohols, terpenes, and terpenes derivatives, volatile fatty acids and other compounds

243 such as the norisoprenoids $\beta$-damascenone and the aldehyde furfural. Most of them have

244 a fermentative origin, although some terpenes were chosen because of their varietal

245 origin. The concentration, calculated for the volatile compounds, was in agreement with

246 other studies focused on the aroma of Grenache rosé wines ${ }^{[18-20]}$. As can be seen in

247 Table 3, the concentration of many volatile compounds in wines aged 1 month was very

248 similar in both types of wines. However, some esters, such as isoamyl, hexyl and 2-

249 phenyl ethyl acetates and some long chain ethyl esters (octanoate, decanoate,

250 dodecanoate) showed higher concentration values in the GSH-IDY-wine. In addition,

251 the concentration of the three fatty acids (hexanoic, octanoic and decanoic) also showed

252 higher concentration in the wines supplemented with the preparation.

254 To know if there was a natural grouping of the wine samples based on the addition of

255 GSH enriched IDY during winemaking, a cluster analysis was performed with the data corresponding to the concentration of volatile compounds in both types of wines during

257 their shelf-life (1, 2, 3 and 9 months old wines). The results are shown in Figure 1. As 258 can be seen, the dendrogram is showing two separated groups of wines. The first one 259 corresponded to wines of 3 and less than 3 months old, and the second one, included all 260 the wines of 9 months. In addition, within each of these two large groups of samples, 261 the figure is revealing a clear separation between wines depending on the addition or not 262 of the GSH-IDY preparation. These results are showing a major influence of the aging 
263 time on wine volatile composition, but also an effect of the addition of the GSH-IDY 264 preparation.

266 Taking into account these results, one-way ANOVA was made to test the effect of time

267 in the volatile composition in each type of wine (Table 3). As can be seen, differences

268 in the evolution of the volatile compounds during the shelf-life of both types of wines

269 were found. Most of the esters decreased during shelf-life in both type of wines, which

270 might be associated to their slow hydrolysis at wine $\mathrm{pH}^{[21]}$. In addition, specific

271 interactions between some esters with some components from the IDY preparations

272 (glycopeptides) have been shown ${ }^{[22,23]}$. However, the higher concentration of esters in

273 the 9 moth GSH-IDY wine compared to the 9 month control wines, might be related to

274 the higher pool of these compounds available, because of the promotion of their

275 production during the alcoholic fermentation due to the extra supplementation in

276 nitrogen compounds by the IDY preparation ${ }^{[8,23,24] .}$ In fact, the sum of free amino acids

277 recently determined in the same wines after the alcoholic fermentation was two times

278 higher in the GSH-IDY wine compared to the Control wine ${ }^{[9]}$.

280 Moreover, the concentration of some terpenes, associated to citric and flowery notes,

281 remained unchanged or even showed a slight increase during the aging of wines.

282 Although during wine aging a slow oxidation of these compounds could have been

283 accounted for, an increase in their concentration may also be possible as a consequence

284 of their spontaneous synthesis from precursors naturally occurring in wines, as has been

285 previously hypothesized ${ }^{[25]}$ or, as in the case of linalool, because it can be formed from

286 other monoterpenoids ${ }^{[26] .}$ The slight increase of linalool during the shelf-life in wines

287 supplemented with the GSH-IDY preparation compared to the control wines may 
indicate a lower oxidation of these compounds in these wines compared to the control

289 wines. Recent research has also shown the antioxidant properties of the $<5000 \mathrm{Da}$

290 fraction isolated from GSH-IDY against some terpenes in synthetic wines submitted to

291 accelerated aging conditions ${ }^{[10]}$.

293 Contrary to most of the studied volatile compounds, fatty acids (octanoic and decanoic)

294 increased in the control wines during aging, while remained practically unchanged in the GSH-IDY wines. In addition, significant differences were found between the two types of wines regarding the alcohol content. The concentration of all the alcohols,

297 except benzenemethanol remained constant during shelf life in the GSH-IDY wines,

298 while decreased in the control wines. This could be due to their oxidation to the 299 corresponding aldehydes. Although the role of GSH-IDY preparations on the volatile 300 compounds have not been studied so far, different authors have shown that the addition 301 of glutathione to wines just before bottling at concentration above $20 \mathrm{mg} \mathrm{L}^{-1}$ might 302 prevent the decrease of terpenic alcohols such as linalool ${ }^{[27,28]}$ and aromatic esters ${ }^{[28,29]}$ 303 during the storage of wines. Previous research performed with the same wines [9] 304 reported higher concentration of GSH in the GSH-IDY wines compared to the control 305 wines. In fact, GSH-IDY wines showed a concentration of GSH about $16 \mathrm{mg} \mathrm{L}^{-1}$, which 306 was higher than the concentrations of GSH reported to have an antioxidant effect in 307 synthetic wine ${ }^{[28] .}$ However, in the above cited work, it has been showed that most of 308 the GSH released from IDY is rapidly oxidized, so the protective effect of GSH on 309 some volatile compounds might be very limited in winemaking conditions. Nonetheless, 310 GSH released by the IDY preparations may also have had an effect in the must, 311 protecting it from oxidation in the first steps during winemaking. In this case, wines 312 might have a longer shelf-life due to the higher concentration of odour active esters and 
313 a better preservation of varietal aromas ${ }^{[30]}$. However it will be necessary in future

314 works to check this hypothesis by systematically sampling during the fermentation step.

315 Besides the differences noticed in the volatile profile between GSH-IDY and control

316 wines, it was very important to know if these changes are also relevant for the sensory

317 properties of the wines.

319 Triangle tests during the shelf-life of wines

321 Triangle tests were performed to find out if there were sensory differences between

322 GSH-IDY and control wines during their shelf-life. Therefore, they were periodically

323 performed (at 1, 2, 3 and 9 months) until sensory differences were perceived. The

324 numbers of correct answers in each triangle test were five, six, four and eight for the 1,

3252,3 and 9 months wines respectively. Therefore, control and GSH-IDY wines were not

326 perceived as different in the just finished wine $(1$ month wine) $(\mathrm{p} \leq 0.05)$ and neither

327 during the early shelf-life of the wines ( 2 and 3 months) $(\mathrm{p} \leq 0.05)$. This is evidencing a

328 slow evolution in the sensory characteristics of the wines during the first months of

329 aging, which is in agreement with the little evolution of the volatile profile found during

330 the three firsts months of aging (Figure 1). These results are indicating that in spite of

331 the supplement in GSH and mainly in nitrogen compounds due to the addition of GSH-

332 IDY preparations into the must ${ }^{[9]}$, the impact of these preparations in the sensory

333 characteristics of wines during the first stages of their shelf-life is relatively low.

334 Different authors have shown that supplementation in nitrogen compounds to the must

335 may affect the production of sulfur compounds ${ }^{[31]}$, medium-chain fatty acid esters and

336 acetic acid [32], whereas other authors claimed that must supplementation with

337 ammonium brings about a decrease in sulphur notes and an increase in the citric flavour 
${ }^{[33]}$. Although the addition of GSH-IDY may slightly increase the volatile acidity of

339 wines (Table 1), it did not provoke sensory differences among IDY wine and control

340 wine after winemaking nor in wines aged 2 and 3 months. Wines were, however,

341 perceived as different after 9 months of aging ( $\mathrm{p} \leq 0.05$ ), which also is in agreement

342 with the highest differences found in their volatile profile.

344 Descriptive analysis

346 To determine which sensory attributes of Grenache wines were the most affected by the

347 addition of the GSH-IDY preparation into the must, descriptive analysis was performed

348 in the 9-month old wines (since, as was evidenced in the triangle test only after 9

349 months differences between the control and GSH-IDY wines were statistically

350 significant). To do so, 12 sensory attributes of Grenache wines were selected on the

351 basis of previous studies performed on the sensory characteristics of Grenache wines

$3522^{[34,18,19]}$ and accordingly to the opinion of eight wine sensory experts. All the attributes

353 were typical of rosé young Grenache wines, and they belonged to the fruity (strawberry,

354 peach, banana, apple and lemon aromas), floral and vegetative (grassy) aromas. In

355 addition, other attributes were chosen to evoke sweet aromas, such as raisin, toffee and

356 honey aromas, since they can be found in some oxidized young wines ${ }^{[1,2,35,36]}$. Yeast

357 aroma was also included because it has been associated to wines supplemented with

358 IDY in a previous work ${ }^{[11]}$ Finally, acidity was also evaluated as a taste attribute

359 because is a typical characteristic of young wines.

361 After the first training session, only those attributes marked above 4, in the $15 \mathrm{~cm}$-scale

362 at least in one of the wines under study were selected. These attributes were strawberry, 
363 peach, banana, yeast and floral aromas, and acid taste. The fact that judges did not

364 score higher than 4 the attributes honey, toffee or raisin, indicated the low presence of

365 sweet-aroma-related notes and therefore, the low grade of oxidation in these wines.

366

367 Once the first training session was concluded, a specific training in the selected

368 attributes at two concentrations was carried out, as has been recommended by Noble

369 and Lesschaeve ${ }^{[37] .}$. A training evaluation was carried out in order to verify the correct

370 training of the panel, and also to detect those judges who were using an inconsistent

371 term respect to the other subjects. All the data from the training evaluation were

372 submitted to analysis of variance (two-way ANOVA). Interaction plot revealed that

373 judges 1 and 10 did not properly rate the intensity of strawberry and banana aromas,

374 and consequently, their scores for these attributes were removed from the training and

375 wine evaluations. Table 4 showed the F-ratios of concentration, judge and

376 concentration $\mathrm{x}$ judge of the ANOVA without taking into account the scores of judges 1

377 and 10 in the attributes strawberry and banana, respectively. As can be seen, the

378 concentration was significantly different for all the studied attributes, whereas,

379 practically no significant effect was found for judges and concentration $\mathrm{x}$ judge.

380 Concentration $\mathrm{x}$ judge was not obtained for acidity as the judges evaluate it only once.

381 Therefore, it can be concluded that in general, the two concentrations for each attribute

382 were perceived as different and all the judges used the same part of the scale and rated

383 the attributes in a similar way. Then, the panel was considered as reliable and consistent

384 with respect to all the attributes, thus well-trained in these descriptors to carry out the 385 wine evaluation. 
387 The wine evaluation was performed once (in both types of wines) in a single session

388 once the consistence of the panel was tested. Analysis of variance (ANOVA) was 389 performed in each attribute to determine if wines were perceived as different, and least

390 significant differences between wine means were computed by a t-test. Table 5 shows

391 F-ratios and p-values of each attribute, discarding the scores for strawberry and banana

392 of judges 1 and 10. The attributes significantly different in both wines are presented in

393 bold in the table. In addition, the mean intensity rating for control and GSH-IDY wines

394 have been plotted in a cobweb graph to get a sensory profile of each type of wine

395 (Figure 2). In this diagram, the centre of the figure represents the lowest intensity with

396 respect to each descriptor increasing to an intensity of 15 at the end of the axes

397 (corresponding to the maximum rating in the $15 \mathrm{~cm}$ unstructured scale). As can be seen

398 in Table 5, acidity was rated the same in the control and GSH-IDY wine. As it can be

399 expected, acidity had the same intensity in both wines, as there was no evidence that the

400 GSH-IDY addition may modify the acidity of wines. In spite of having different

401 concentrations in volatile compounds typically associated to flowery notes, such as 2-

402 phenylethyl acetate ${ }^{[18,38]}$, both wines presented similar intensities in floral aroma.

403 Regarding fruit attributes, GSH-IDY wine exhibited almost the double intensity in

404 strawberry notes (1.98 times more) and also in the banana attribute (1.58 times more)

405 than the control wine. These attributes can be related to a higher concentration of esters

406 related to fruity aroma in the 9 months GSH-IDY wine compared to the control wine.

407 For instance, the concentration of isoamyl acetate, a volatile compound typically

408 associated to banana flavour was $446 \mathrm{mg} \mathrm{L}^{-1}$ in the 9-month GSH-IDY wine while it

409 was of $189 \mathrm{mg} \mathrm{L}^{-1}$ in the control wine. However, control wines were more intense in

410 peach aroma. The yeast aroma attribute was included in this study because it has been

411 previously shown that the sensory profile of IDY preparations might include odorant 
412 compounds with yeast-like notes ${ }^{[11] .}$ In the above mentioned work, authors showed that

413 yeast-like notes may mask some typical varietal aromatic notes in wines. Therefore, its

414 presence in young wines may decrease the aroma quality. However, in the present work,

415 GSH-IDY wines were rated lower in yeast-like notes compared to the control wine. The

416 possible release of other odorant molecules, such as pyrazines present in these

417 preparations ${ }^{[11,39]}$ and typically associated to roasted, toasted, popcorn aromatic notes

418 may have masked the characteristic typical yeast odour associated to fermentation yeast,

419 although in this work, the amount of IDY added to the musts was not very high $\left(2 \mathrm{mg} \mathrm{\textrm {L } ^ { - }}\right.$

$42{ }^{1}$ ) and it has been shown that the appearance of the yeast-like notes is associated to a

421 higher dose of IDY in wines (150-600 $\left.\mathrm{mg} \mathrm{L}^{-1}\right)^{[11]}$. Finally, it is important to emphasize

422 that during the training, the panel identified the yeast aroma as an off-flavor, being

423 related to sulphur-like aroma. Therefore, the higher intensity in yeast aroma in the

424 control wine might have been perceived by the panel as a symptom of lower aroma 425 quality compared to the GSH-IDY wine.

426

427 Consumer tests

428

429 Finally, consumer tests were carried out in order to determine if wine consumers could

430 perceive preferences towards some of the wines. On a 9 point hedonic scale, consumers

431 rated their liking of the control and GSH-IDY wines in 6.12 and 5.92 respectively,

432 which indicated that the acceptability for both types of wines was in general good.

433 However, no significant differences in consumer preferences were found between both

434 types of wines, and neither when the sex or the age of the consumers were taken into

435 consideration (data not shown). These results showed that consumers did not evidence

436 preference patterns towards wines made with GSH-IDY addition. Nevertheless, a 
greater consumers sample size could improve both, an increase of discrimination power

438 between wines and the representativeness of the consumers population, indicating a

439 future line of research to be explored.

440

\section{CONCLUSIONS}

443 The addition of glutathione enriched IDY preparations into Grenache musts during 444 winemaking has an impact on the volatile profile of young rosé wines during aging that 445 can be responsible for sensory differences in the later stages of wine shelf-life (above 9 446 months). In general, wines supplemented with a glutathione enriched IDY preparation 447 are more intense in typical fruity attributes of young rosé wines (banana, strawberry), 448 which could be related at least in part by the protection of some aroma compounds 449 against oxidation, likely in the first steps during winemaking. However, the changes in 450 the sensory profile could be also related to other effects linked to the addition of IDYs 451 into wines, such as the release of volatile compounds and/or the effect of yeast 452 macromolecules on aroma volatility. In addition, the influence of IDY in the 453 fermentation might have change yeas metabolic by-products inducing changes in wine sensory characteristics. Nonetheless, the sensory effect is not evident enough to show consumer preferences towards GSH-IDY wines. Finally, although the use of industrial manufacturing conditions has allowed to us a valuable study of the use of GSH-IDY

457 preparations in real winery conditions, new research, using more wine samples with 458 other GSH-IDY preparations and industrially manufactured is necessary, in order to 459 fully understand the chemistry beyond the use of these preparations, during 460 winemaking. 
463 This work forms part of the project PET 2007-0134 funded by the Ministry of Science 464 and Innovation of Spain. Authors are grateful to Virginia Fernandez-Ruiz for her 465 assistance on panel preliminary training and to judges and consumers for their 466 participation in the sensory analysis. IAO greatly acknowledge the Comunidad de 467 Madrid for her research contract. 


\section{REFERENCES}

470 1. Bueno M, Cullere. L., Cacho, J., Ferreira, V. Chemical and sensory characterization of oxidative behaviour in different wines. Food Research International, 2010, $43,1423-1428$

2. Escudero A, Asensio E, Cacho J, Ferreira V. Sensory and chemical changes of young white wines stored under oxygen. An assessment of the role played by aldehydes and some other important odorants. Food Chemistry, 2002, 77 (3), 325-331

3. Escudero A, Cacho J, Ferreira V (2000) Isolation and identification of odorants generated in wine during its oxidation: a gas chromatography-olfactometric study. European Food Research and Technology 2000, 211 (2), 105-110

4. Singleton VL. Oxygen with Phenols and Related Reactions in Musts, Wines, and Model Systems - Observations and Practical Implications. American Journal of Enology and Viticulture 1987, 38 (1), 69-77

5. Lavigne-Cruege V, Pons, A., Chone, X. \& Dubordieu, D. Ròle du glutathion sur l'evolution aromatique des vins blancs secs. In: Oenologie VII sympoium International d'oenologie. Tec\&Doc, 2003, 385-388

6. El Hosry L, Auezova L, Sakr A, Hajj-Moussa E. Browning susceptibility of white wine and antioxidant effect of glutathione. International Journal of Food Science and Technology 2009, 44 (12), 2459-2463.

7. Vaimakis V, Roussis IG (1996) Must oxygenation together with glutathione addition in the oxidation of white wine. Food Chemistry, 1996, 57 (3), 419-422

8. Pozo-Bayon MA, Andujar-Ortiz I, Moreno-Arribas MV. Scientific evidences beyond the application of inactive dry yeast preparations in winemaking. Food Research International, 2009, 42 (7), 754-761.

9. Andujar-Ortiz I, Pozo-Bayon MA, Moreno-Arribas MV, Martin-Alvarez PJ, Rodriguez-Bencomo JJ. Reversed-phase high-performance liquid-chromatographyfluorescence detection for the analysis of glutathione and its precursor $\gamma$-glutamylcysteine in wines and model wines supplemented with oenological inactive dry yeast preparations, Food Analytical Methods, 2012, 5, 154-161.

10. Rodriguez-Bencomo JJ, Andujar-Ortiz I, Moreno-Arribas MV, Pozo-Bayon MA (Effect of isolated fractions from glutathione enriched-inative dry yeast on the oxidation of wine terpenes. In: Proceedings from the II Wine Active Compounds (WAC) Congress, 2011, Beaune (France). 
11. Comuzzo P, Tat L, Tonizzo A, Battistutta F. Yeast derivatives (extracts and autolysates) in winemaking: Release of volatile compounds and effects on wine aroma volatility. Food Chemistry, 2006, 99 (2), 217-230.

12. Guadalupe Z, Palacios A, Ayestaran B. Maceration enzymes and mannoproteins: A possible strategy to increase colloidal stability and color extraction in red wines. Journal of Agricultural and Food Chemistr, 2007, 55 (12), 4854-4862.

13. International Organisation of Wine (OIV). Recueil des méthodes internationales dánalyse des vins et des mouts. In: Complément $\mathrm{n}^{\circ} 1$ à l'edition officielle de juin 1990, 1990, OIV, Paris.

14. Rodriguez-Bencomo JJ, Muñoz-Gonzalez C, Andujar-Ortiz I, Martin-Alvarez PJ, Moreno-Arribas MV, Pozo-Bayon MA Assessment of the effect of the non-volatile wine matrix on the volatility of typical wine aroma compounds by HS-SPME-GCMS analysis. Journal of the Science of Food and Agricultural, 2011, 91, 2484-2494

15. ISO 8586-1 (1993) Sensory analysis-General guidance-Part 1: selected assessors.

16. ISO 4120 (2004) Sensory analysis-Methodology-Triangle test.

17. O'Mahony Sensory evaluation of food: statistical methods and procedures. 1986 Marcel Dekker, Inc., New York

18. Ferreira V, Lopez R, Escudero A, Cacho JF. The aroma of Grenache red wine: Hierarchy and nature of its main odorants, Journal of the Science of Food and Agricultural. 1998, 77 (2) 259-267

19. Ferreira V, Ortin N, Escudero A, Lopez R, Cacho J. Chemical characterization of the aroma of Grenache rose wines: Aroma extract dilution analysis, quantitative determination, and sensory reconstitution studies, Journal of Agricultural and Food Chemistry. 2002, 50 (14), 4048-4054.

20. López R, Ezpeleta, E., Sánchez, I., Cacho, J., Ferreira, V. Analysis of the aroma intensities of volatile compounds released from mild acid hydrolysates of odourless precursors extracted from Tempranillo and Grenache grapes using gas chromatography-olfactometry, Food Chemistry. 2004, 88, 95-103

21. Rapp A, Mandery H. Wine Aroma. Experientia. 1986, 42 (8), 873-884

22. Lubbers S, Voilley A, Feuillat M, Charpentier C. Influence of Mannoproteins from Yeast on the Aroma Intensity of a Model Wine. Food Science and TechnologyLWT, 1994, 27 (2), 108-114

23. Pozo-Bayon MA, Andujar-Ortiz I, Alcaide-Hidalgo JM, Martin-Alvarez PJ, Moreno-Arribas MV. Characterization of commercial inactive dry yeast 
preparations for enological use based on their ability to release soluble compounds and their behavior toward aroma compounds in model wines, Journal of Agricultural and Food Chemistry 2009, 57 (22), 10784-10792

24. Feuillat M, Guerreau, J.Les nouveaux activateurs de la fermentation alcoolique. Bulletin OIV. 1996, (789-790), 987-998

25. Jarauta I, Cacho J, Ferreira V. Concurrent phenomena contributing to the formation of the aroma of wine during aging in oak wood: An analytical study, Journal of Agricultural and Food Chemistry 2005, 53 (10), 4166-4177.

26. Pedersen DS, Capone DL, Skouroumounis GK, Pollnitz AP, Sefton MA. Quantitative analysis of geraniol, nerol, linalool, and alpha-terpineol in wine, Analytical and Bioanalytical Chemistry. 2003, 375 (4), 517-522.

27. Papadopoulou D, Roussis IG. Inhibition of the decline of linalool and alphaterpineol in muscat wines by glutathione and n-acetyl-cysteine, Italian Journal of Food Science. 2001, 13 (4), 413-419

28. Papadopoulou D, Roussis IG. Inhibition of the decrease of volatile esters and terpenes during storage of a white wine and a model wine medium by glutathione and $\mathrm{N}$-acetylcysteine, International Journal of Food Science and Technology 2008, 43 (6), 1053-1057.

29. Roussis IG, Lambropoulos I, Tzimas P. Protection of volatiles in a wine with low sulfur dioxide by caffeic acid or glutathione, American Journal of Enology and Viticulture. 2007, 58 (2), 274-278

30. Moio L, Ugliano M, Genovese A, Gambuti A, Pessina R, Piombino P. Effect of antioxidant protection of must on volatile compounds and aroma shelf life of falanghina (Vitis vinifera L.) wine, Journal of Agricultural and Food Chemistry 2004, 52 (4), 891-897.

31. Ugliano M, Fedrizzi B, Siebert T, Travis B, Magno F, Versini G, Henschke PA. Effect of Nitrogen Supplementation and Saccharomyces Species on Hydrogen Sulfide and Other Volatile Sulfur Compounds in Shiraz Fermentation and Wine, Journal of Agricultural and Food Chemistry 2009, 57 (11), 4948-4955.

32. Vilanova M, Ugliano M, Varela C, Siebert T, Pretorius IS, Henschke PA. Assimilable nitrogen utilisation and production of volatile and non-volatile compounds in chemically defined medium by Saccharomyces cerevisiae wine yeats. Applied Microbiology Biotechnology. 2007, 77, 145-157. 
33. Hernandez-Orte P, Ibarz MJ, Cacho J, Ferreira V. Effect of the addition of ammonium and amino acids to musts of Airen variety on aromatic composition and sensory properties of the obtained wine. Food Chemistry. 2005, 89 (2), 163-174.

34. de Andres-de Prado R, Yuste-Rojas M, Sort X, Andres-Lacueva C, Torres M, Lamuela-Raventos RM. Effect of soil type on wines produced from Vitis vinifera L. Cv. Grenache in commercial vineyards. Journal of Agricultural and Food Chemistry. 2007, 55, 779-786.

35. Esti M, Airola RLG, Moneta E, Paperaio M, Sinesio F. Qualitative data analysis for an exploratory sensory study of grechetto wine, Analytical Chimica Acta. 2010, 660 (1-2), 63-67.

36. Gonzalez-Vinas MA, Perez-Coello MS, Cabezudo MD, Martin-Alvarez PJ. Sensory analysis of aroma attributes of young Airen white wines during storage in the bottle, Journal of Food Quality. 1998, 21 (4), 285-297

37. Noble AC, Lesschaeve, I. Sensory methods of flavour analysis. In: Taylor AJ, Linforth, R.S.T. (ed) Food Flavour Technology 2010. Blackwell, Chichester (United Kingdom),

38. Campo E, Ferreira V, Escudero A, Cacho J. Prediction of the wine sensory properties related to grape variety from dynamic-headspace gas chromatographyolfactometry data, Journal of Agricultural and Food Chemistry. 2005, 53 (14), 56825690.

39. Pozo-Bayon MA, Andujar-Ortiz I, Moreno-Arribas MV. Volatile profile and potential of inactive dry yeast-based winemaking additives to modify the volatile composition of wines. Journal of the Science of Food and Agricultural. 2009, 89

C-1: Include complete journal titles in all cases?

595 Done

C-2: Include couple of recent references (last 2 years) from IJFP?

597 Sorry, but we did not find any recent article published in the IJFP related with the topic of the present manuscript. 
600 Table 1. Evolution of global composition in the must, control wine and in the wine

601 supplemented with the glutathione enriched IDY preparation.

602

\begin{tabular}{llccccc}
\hline & & $\mathrm{pH}$ & $\mathrm{TA}^{\mathrm{a}}$ & $\mathrm{PAD}^{\mathrm{b}}$ & $\mathrm{AD}^{\mathrm{c}}$ & $\mathrm{VA}^{\mathrm{d}}$ \\
\hline Must & & 3.2 & 3.7 & 13.9 & - & - \\
\hline Cont-W & After alcoholic fermentation & 3.13 & 4.2 & - & 13.8 & - \\
& Stabilized and clarified wine & 3.15 & 3.4 & - & 13.75 & 0.16 \\
\hline \multirow{2}{*}{ GSH-IDY-W } & After alcoholic fermentation & 3.18 & 4 & - & 13.6 & - \\
& Stabilized and clarified wine & 3.2 & 3.25 & - & 13.5 & 0.22 \\
\hline Cont-W:Control wine; GSH-IDY-W:Wine supplemented with the gutathione enrichedDY
\end{tabular}

603

604 a: Total acidity (g. sulphuric acid/L)

605 b: Probable alcohol degree (\% v/v)

$606{ }^{c}:$ : Alcohol degree (\% v/v)

607 d: Volatile acidity (g acetic acid/L)

608 


\begin{tabular}{|c|c|c|}
\hline \multirow[b]{2}{*}{ Attributes } & \multicolumn{2}{|c|}{ Reference standard composition $^{\mathrm{a}}$} \\
\hline & Low concentration & High concentration \\
\hline Strawberry & $\begin{array}{l}1.5 \mathrm{~g} \text { of crushed fresh } \\
\text { strawberries }\end{array}$ & $\begin{array}{l}6 \mathrm{~g} \text { of crushed fresh } \\
\text { strawberries }\end{array}$ \\
\hline Peach & $2 \mathrm{~mL}$ of peach nectar & $7.5 \mathrm{~mL}$ of peach nectar \\
\hline Banana & $\begin{array}{c}1 / 410 \mathrm{~mm} \text { slice fresh } \\
\text { banana }\end{array}$ & $10 \mathrm{~mm}$ slice fresh banana \\
\hline Apple & - & $\begin{array}{l}\text { Slice fresh apple, } 5 \mathrm{~mL} \text { apple } \\
\text { juice }\end{array}$ \\
\hline Lemon & - & $\begin{array}{l}5 \mathrm{~mL} \text { lemon juice, and small } \\
\text { peel piece of fresh fruit }\end{array}$ \\
\hline Floral & $\begin{array}{c}0.2 \mathrm{ml} \text { of linalool solution } \\
(150 \mathrm{mg} / \mathrm{L})\end{array}$ & $\begin{array}{c}1.5 \mathrm{~mL} \text { of a linalool solution } \\
(150 \mathrm{mg} / \mathrm{L})\end{array}$ \\
\hline Grassy & - & $\begin{array}{l}1 \mathrm{~mL} \text { of a cis-3-hexen-1-ol } \\
\text { solution }(100 \mathrm{mg} / \mathrm{L})\end{array}$ \\
\hline Toffee & - & 1 toffee candy \\
\hline Raisin & - & $2-3$ crushed fresh raisins \\
\hline Honey & - & $8 \mathrm{~mL}$ honey \\
\hline Yeast & $0.25 \mathrm{~g}$ baker yeast & $1 \mathrm{~g}$ baker yeast \\
\hline Acidity & $0.2 \mathrm{~g} / \mathrm{L}$ citric acid in water & $0.8 \mathrm{~g} / \mathrm{L}$ citric acid in water \\
\hline
\end{tabular}

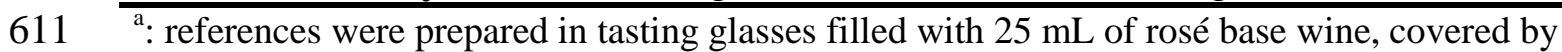

612 petri dishes, with the exception for acidity that was prepared in water. Attributes in bold were 613 finally selected for the study. 
615 with the G-IDY preparation (GSH-IDY-W) at 1,2, 3 and 9 months of aging ( $1 \mathrm{~m}, 2 \mathrm{~m}, 3 \mathrm{~m}$ and $9 \mathrm{~m}$, respectively)

\begin{tabular}{|c|c|c|c|c|c|c|c|c|c|c|c|c|}
\hline & \multirow[b]{2}{*}{ Compounds } & \multirow[b]{2}{*}{ RIexp $\dagger$} & \multirow[b]{2}{*}{ Rilit: } & \multirow[b]{2}{*}{$\mathrm{Id} \S$} & \multicolumn{4}{|c|}{ Cont-W } & \multicolumn{4}{|c|}{ GSH-IDY-W } \\
\hline & & & & & $1 \mathrm{~m}$ & $2 \mathrm{~m}$ & $3 \mathrm{~m}$ & $9 \mathrm{~m}$ & $1 \mathrm{~m}$ & $2 \mathrm{~m}$ & $3 \mathrm{~m}$ & $9 \mathrm{~m}$ \\
\hline \multirow{14}{*}{ 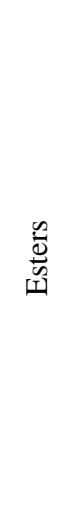 } & Ethyl propanoate & 920 & 903 & $\mathrm{~S}, \mathrm{R}, \mathrm{M}$ & $43.9^{b} \pm 2.6$ & $46.3^{b} \pm 5.3$ & $39.5^{\mathrm{b}, \mathrm{a}} \pm 6.9$ & $26.8^{\mathrm{a}} \pm 2.6$ & $26.5^{\mathrm{a}} \pm 0.6$ & $29.3^{\mathrm{a}} \pm 1.2$ & $33^{\mathrm{a}} \pm 0.1$ & $30.9^{\mathrm{a}} \pm 5.1$ \\
\hline & Isobutyl acetate & 975 & 953 & $\mathrm{~S}, \mathrm{R}, \mathrm{M}$ & $4.5^{\mathrm{b}} \pm 0.4$ & $4.1^{\mathrm{b}} \pm 0.94$ & $3.3^{\mathrm{b}} \pm 0.7$ & $1.4^{\mathrm{a}} \pm 0.2$ & $5.0^{\mathrm{b}} \pm 0.3$ & $4.5^{\mathrm{b}} \pm 0.0$ & $4.6^{\mathrm{b}} \pm 0.1$ & $2.7^{\mathrm{a}} \pm 0.3$ \\
\hline & Ethyl butanoate & 1010 & 1010 & $\mathrm{~S}, \mathrm{R}, \mathrm{M}$ & $240.7^{\mathrm{b}} \pm 12.6$ & $225.2^{\mathrm{b}} \pm 41.6$ & $200.7^{\mathrm{b}} \pm 38.8$ & $103.2^{\mathrm{a}} \pm 22.6$ & $237.8^{\mathrm{b}} \pm 7.2$ & $229.9^{\mathrm{b}} \pm 4.9$ & $242.0^{\mathrm{b}} \pm 2.1$ & $173.2^{\mathrm{a}} \pm 18.9$ \\
\hline & Ethyl 2-methylbutanoate & 1026 & 1031 & $\mathrm{~S}, \mathrm{R}, \mathrm{M}$ & $2.5^{\mathrm{b}} \pm 0.1$ & $2.4^{\mathrm{b}} \pm 0.4$ & $2.7^{\mathrm{b}} \pm 0.5$ & $2.5^{\mathrm{a}} \pm 0.2$ & $1.7^{\mathrm{a}} \pm 0.1$ & $2^{\mathrm{a}, \mathrm{b}} \pm 0.1$ & $2.2^{\mathrm{b}, \mathrm{c}} \pm 0.1$ & $2.6^{c} \pm 0.2$ \\
\hline & Isoamyl acetate & 1115 & 1117 & $\mathrm{~S}, \mathrm{R}, \mathrm{M}$ & $573.7^{\mathrm{b}} \pm 16.6$ & $479^{\mathrm{b}} \pm 75.1$ & $390.1^{\mathrm{b}} \pm 79.5$ & $188.6^{\mathrm{a}} \pm 27.0$ & $811^{\mathrm{c}} \pm 22.5$ & $786.2^{\mathrm{c}} \pm 1.2$ & $730.6^{\mathrm{b}} \pm 3.7$ & $445.9^{\mathrm{a}} \pm 17.3$ \\
\hline & Ethyl hexanoate & 1229 & 1230 & $\mathrm{~S}, \mathrm{R}, \mathrm{M}$ & $710.3^{\mathrm{b}} \pm 6.8$ & $582^{\mathrm{b}} \pm 70.8$ & $574.6^{\mathrm{b}} \pm 106.8$ & $310.7^{\mathrm{a}} \pm 28.6$ & $706^{\mathrm{b}} \pm 13.1$ & $722.4^{\mathrm{b}} \pm 7.4$ & $716.6^{\mathrm{b}} \pm 7.5$ & $467.1^{\mathrm{a}} \pm 28.3$ \\
\hline & Hexyl acetate & 1267 & 1269 & $\mathrm{~S}, \mathrm{R}, \mathrm{M}$ & $130.7^{\mathrm{b}} \pm 2.06$ & $110.1^{\mathrm{b}} \pm 14.3$ & $97.7^{\mathrm{b}} \pm 19.1$ & $44.9^{\mathrm{a}} \pm 4.7$ & $219.6^{\mathrm{c}} \pm 6.3$ & $213^{\mathrm{c}} \pm 0.5$ & $194.6^{\mathrm{b}} \pm 1.9$ & $114.5^{\mathrm{a}} \pm 3.5$ \\
\hline & Ethyl heptanoate & 1327 & 1332 & $\mathrm{R}, \mathrm{M}$ & $2.1^{\mathrm{b}} \pm 0.1$ & $1.8^{\mathrm{b}} \pm 0.2$ & $1.9^{\mathrm{b}} \pm 0.4$ & $1.1^{\mathrm{a}} \pm 0.2$ & $1.4^{\mathrm{b}} \pm 0.1$ & $1.5^{\mathrm{b}} \pm 0.0$ & $1.4^{\mathrm{b}} \pm 0.1$ & $0.8^{\mathrm{a}} \pm 0.1$ \\
\hline & Ethyl octanoate & 1429 & 1431 & $\mathrm{~S}, \mathrm{R}, \mathrm{M}$ & $1678.8^{\mathrm{b}} \pm 306.8$ & $1745.1^{\mathrm{b}} \pm 146.2$ & $1788.4^{\mathrm{b}} \pm 145.8$ & $666.1^{\mathrm{a}} \pm 31.7$ & $2097.7^{\mathrm{b}} \pm 8.4$ & $2104.3^{\mathrm{b}} \pm 9.1$ & $2197.4^{c} \pm 14.7$ & $1046.1^{\mathrm{a}} \pm 13$ \\
\hline & Ethyl nonanoate & 1530 & 1541 & $\mathrm{~S}, \mathrm{R}, \mathrm{M}$ & $1.9^{\mathrm{a}} \pm 0.7$ & $3.8^{\mathrm{a}} \pm 0.2$ & $4.6^{\mathrm{a}} \pm 0.2$ & $4.40^{\mathrm{a}} \pm 2.4$ & $2.9^{\mathrm{a}} \pm 0.1$ & $3.6^{\mathrm{b}} \pm 0.0$ & $4.1^{\mathrm{b}} \pm 0.2$ & $2.4^{\mathrm{a}} \pm 0.4$ \\
\hline & Ethyl decanoate & 1634 & 1634 & $\mathrm{~S}, \mathrm{R}, \mathrm{M}$ & $511.9^{\mathrm{a}, \mathrm{b}} \pm 253.0$ & $883.5^{\mathrm{c}} \pm 37$ & $864.3^{b, c} \pm 47.1$ & $270^{\mathrm{a}} \pm 15$ & $931.6^{\mathrm{b}} \pm 55$ & $960.3^{\mathrm{b}} \pm 12.7$ & $1045.2^{\mathrm{b}} \pm 56.9$ & $398.4^{\mathrm{a}} \pm 44.3$ \\
\hline & Diethyl succinate & 1673 & 1694 & $\mathrm{~S}, \mathrm{R}, \mathrm{M}$ & $515.3^{\mathrm{a}} \pm 62.7$ & $492.4^{\mathrm{a}} \pm 5.8$ & $788^{\mathrm{b}} \pm 97.4$ & $1035.8^{\mathrm{b}} \pm 150.8$ & $279.1^{\mathrm{a}} \pm 17.1$ & $300^{\mathrm{a}} \pm 21.3$ & $436.4^{\mathrm{a}} \pm 33.6$ & $800.2^{\mathrm{b}} \pm 230.2$ \\
\hline & 2-Phenyl ethyl acetate & 1809 & 1752 & $\mathrm{~S}, \mathrm{R}, \mathrm{M}$ & $49.4^{\mathrm{b}} \pm 1.3$ & $53.3^{c} \pm 0.4$ & $53.6^{c} \pm 0.4$ & $42.6^{\mathrm{a}} \pm 1.9$ & $89.4^{\mathrm{a}} \pm 5.8$ & $84.2^{\mathrm{a}} \pm 3.7$ & $95.6^{\mathrm{a}} \pm 0.6$ & $63.7^{\mathrm{a}} \pm 23.3$ \\
\hline & Ethyl dodecanoate & 1840 & 1833 & $\mathrm{~S}, \mathrm{R}, \mathrm{M}$ & $36.8^{\mathrm{a}} \pm 15.0$ & $72^{\mathrm{a}} \pm 1.8$ & $49.9^{\mathrm{a}} \pm 5.9$ & $97.1^{\mathrm{a}} \pm 40.8$ & $82.3^{\mathrm{a}} \pm 15.5$ & $65.7^{\mathrm{a}} \pm 8.5$ & $52.4^{\mathrm{a}} \pm 4.9$ & $63.5^{\mathrm{a}} \pm 12.7$ \\
\hline \multirow{5}{*}{$\begin{array}{l}n \\
0 \\
0 \\
0 \\
0 \\
\frac{0}{<}\end{array}$} & 1-Butanol & 1141 & 1157 & $\mathrm{~S}, \mathrm{R}, \mathrm{M}$ & $394.8^{\mathrm{b}} \pm 9.9$ & $380.6^{\mathrm{b}} \pm 65.7$ & $343.1^{\mathrm{a}, \mathrm{b}} \pm 39.2$ & $226.9^{\mathrm{a}} \pm 37.5$ & $333.7^{\mathrm{a}} \pm 8.3$ & $310.7^{\mathrm{a}} \pm 10.5$ & $361.5^{\mathrm{a}} \pm 10.5$ & $322.4^{\mathrm{a}} \pm 66.9$ \\
\hline & 1-Hexanol & 1353 & 1356 & $\mathrm{~S}, \mathrm{R}, \mathrm{M}$ & $1255.6^{\mathrm{b}} \pm 100.6$ & $1122.7^{\mathrm{a}, \mathrm{b}} \pm 170.9$ & $1102.7^{\mathrm{a}, \mathrm{b}} \pm 215$ & $756.4^{\mathrm{a}} \pm 116.8$ & $864.6^{\mathrm{a}} \pm 17.3$ & $718.7^{\mathrm{a}} \pm 15.4$ & $877.9^{\mathrm{a}} \pm 22.4$ & $893.6^{\mathrm{a}} \pm 211.8$ \\
\hline & Cis-3-hexenol & 1361 & 1370 & $\mathrm{~S}, \mathrm{R}, \mathrm{M}$ & $44.4^{\mathrm{b}} \pm 3.4$ & $40.7^{\mathrm{a}, \mathrm{b}} \pm 5.1$ & $40.3^{\mathrm{a}, \mathrm{b}} \pm 6.9$ & $28.4^{\mathrm{a}} \pm 2.5$ & $38.4^{\mathrm{a}} \pm 1.1$ & $31.2^{\mathrm{a}} \pm 0.2$ & $39.7^{\mathrm{a}} \pm 0.3$ & $37.3^{\mathrm{a}} \pm 8.8$ \\
\hline & Trans-3-hexenol & 1378 & 1370 & $\mathrm{~S}, \mathrm{R}, \mathrm{M}$ & $58.6^{\mathrm{b}} \pm 2.2$ & $61.5^{\mathrm{b}} \pm 1.0$ & $57.2^{\mathrm{b}} \pm 6.6$ & $39.3^{\mathrm{a}} \pm 5.8$ & $69^{\mathrm{a}} \pm 0.1$ & $59.6^{\mathrm{a}} \pm 1.3$ & $73.0^{\mathrm{a}} \pm 1.2$ & $68.6^{\mathrm{a}} \pm 15.7$ \\
\hline & Benzenemethanol & 1880 & 1834 & $\mathrm{~S}, \mathrm{R}, \mathrm{M}$ & $79.6^{\mathrm{a}, \mathrm{b}} \pm 7.0$ & $68.4^{\mathrm{a}} \pm 0.9$ & $83.6^{\mathrm{a}, \mathrm{b}} \pm 9.7$ & $86^{\mathrm{b}} \pm 3.4$ & $77.8^{\mathrm{a}} \pm 3.2$ & $71^{\mathrm{a}} \pm 6.7$ & $97.4^{\mathrm{a}} \pm 8.0$ & $96.9^{\mathrm{a}} \pm 33.5$ \\
\hline \multirow{6}{*}{ 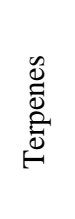 } & Limonene & 1179 & 1180 & $\mathrm{~S}, \mathrm{R}, \mathrm{M}$ & $0.4^{\mathrm{a}} \pm 0.0$ & $0.3^{\mathrm{a}} \pm 0.0$ & $0.4^{\mathrm{a}} \pm 0.0$ & $1.1^{\mathrm{a}} \pm 0.6$ & $0.5^{\mathrm{a}} \pm 0.2$ & $0.3^{\mathrm{a}} \pm 0.0$ & $0.4^{\mathrm{a}} \pm 0.0$ & $0.5^{\mathrm{a}} \pm 0.1$ \\
\hline & $\alpha$-terpinene & 1494 & - & M & $1.1^{\mathrm{a}} \pm 0.1$ & $1.2^{\mathrm{a}} \pm 0.1$ & $1.40^{\mathrm{a}, \mathrm{b}} \pm 0.0$ & $1.6^{\mathrm{b}} \pm 0.2$ & $0.8^{\mathrm{a}} \pm 0.0$ & $0.7^{\mathrm{a}} \pm 0.1$ & $1.0^{\mathrm{a}, \mathrm{b}} \pm 0.1$ & $1.3^{\mathrm{b}} \pm 0.2$ \\
\hline & Linalool & 1547 & 1541 & $\mathrm{~S}, \mathrm{R}, \mathrm{M}$ & $3.3^{\mathrm{a}} \pm 0.7$ & $3^{\mathrm{a}} \pm 0.3$ & $3.6^{\mathrm{a}} \pm 0.5$ & $3.3^{\mathrm{a}} \pm 0.5$ & $2.6^{\mathrm{a}} \pm 0.2$ & $2.6^{\mathrm{a}} \pm 0.0$ & $3.3^{\mathrm{a}, \mathrm{b}} \pm 0.1$ & $4.3^{\mathrm{b}} \pm 0.8$ \\
\hline & Citronellyl acetate & 1657 & 1666 & $\mathrm{R}, \mathrm{M}$ & $1.9^{\mathrm{a}, \mathrm{b}} \pm 0.5$ & $2.2^{\mathrm{b}} \pm 0.2$ & $2.1^{\mathrm{a}, \mathrm{b}} \pm 0.2$ & $1.4^{\mathrm{a}} \pm 0.2$ & $2.3^{\mathrm{b}} \pm 0.0$ & $2.1^{\mathrm{a}, \mathrm{b}} \pm 0.6$ & $2.0^{\mathrm{a}, \mathrm{b}} \pm 0.5$ & $1.2^{\mathrm{a}} \pm 0.1$ \\
\hline & $\beta$-Citronellol & 1767 & 1781 & $\mathrm{~S}, \mathrm{R}, \mathrm{M}$ & $4.8^{\mathrm{a}} \pm 1.2$ & $4^{\mathrm{a}} \pm 0.1$ & $4.5^{\mathrm{a}} \pm 0.6$ & $4.8^{\mathrm{a}} \pm 0.1$ & $3.9^{\mathrm{a}} \pm 0.3$ & $3.3^{\mathrm{a}} \pm 0.2$ & $4.2^{\mathrm{a}} \pm 0.2$ & $4.0^{\mathrm{a}} \pm 0.9$ \\
\hline & Isopropyl myristate & 2035 & 2040 & $\mathrm{R}, \mathrm{M}$ & $0.3^{\mathrm{a}} \pm 0.3$ & $0.3^{\mathrm{a}} \pm 0.1$ & $0.3^{\mathrm{a}} \pm 0.0$ & $0.1^{\mathrm{a}} \pm 0.0$ & $0.2^{\mathrm{a}, \mathrm{b}} \pm 0.0$ & $0.4^{\mathrm{c}} \pm 0.0$ & $0.3^{\mathrm{b}, \mathrm{c}} \pm 0.1$ & $0.1^{\mathrm{a}} \pm 0.0$ \\
\hline \multirow{3}{*}{ 预 } & Hexanoic acid & 1859 & 1789 & $\mathrm{~S}, \mathrm{R}, \mathrm{M}$ & $4821.8^{\mathrm{a}} \pm 643.4$ & $3411.1^{\mathrm{a}} \pm 91.7$ & $4812.9^{\mathrm{a}} \pm 683.2$ & $3689.1^{\mathrm{a}} \pm 527.2$ & $5097.7^{\mathrm{a}} \pm 117.6$ & $4988.2^{\mathrm{a}} \pm 152.8$ & $5125.4^{\mathrm{a}} \pm 1016$ & $6153.9^{\mathrm{a}} \pm 1545.1$ \\
\hline & Octanoic acid & 2078 & 1998 & $\mathrm{~S}, \mathrm{R}, \mathrm{M}$ & $2383.2^{\mathrm{a}} \pm 188.4$ & $2247.1^{\mathrm{a}} \pm 39.7$ & $2858.2^{\mathrm{b}} \pm 57.9$ & $3393.4^{\mathrm{c}} \pm 191.2$ & $3240.5^{\mathrm{a}} \pm 194.5$ & $3335.9^{\mathrm{a}} \pm 87.7$ & $3289.6^{\mathrm{a}} \pm 226.0$ & $3731.0^{\mathrm{a}} \pm 1280.8$ \\
\hline & Decanoic acid & 2289 & 2279 & $\mathrm{~S}, \mathrm{R}, \mathrm{M}$ & $438^{\mathrm{a}} \pm 4.2$ & $509.5^{\mathrm{a}, \mathrm{b}} \pm 47.4$ & $585.6^{\mathrm{b}} \pm 32.2$ & $739.5^{c} \pm 29.1$ & $679.9^{\mathrm{a}} \pm 4.6$ & $720.3^{\mathrm{a}} \pm 67.0$ & $802^{\mathrm{a}} \pm 16.7$ & $597.3^{\mathrm{a}} \pm 281.9$ \\
\hline \multirow{5}{*}{$\begin{array}{l}\frac{n}{0} \\
\stackrel{\Xi}{0}\end{array}$} & 2,3 butanedione & 937 & 949 & $\mathrm{~S}, \mathrm{R}, \mathrm{M}$ & $258.7^{\mathrm{a}} \pm 51.6$ & $309.1^{\mathrm{a}} \pm 61.4$ & $280.8^{\mathrm{a}} \pm 59.8$ & $198.1^{\mathrm{a}} \pm 17.8$ & $390.2^{c} \pm 1.6$ & $400.3^{\mathrm{c}} \pm 21.0$ & $310.5^{\mathrm{b}} \pm 24.2$ & $92.8^{\mathrm{a}} \pm 21.9$ \\
\hline & Furfuraldehyde & 1459 & 1449 & $\mathrm{~S}, \mathrm{R}, \mathrm{M}$ & $3^{\mathrm{a}} \pm 0.3$ & $4.5^{\mathrm{a}, \mathrm{b}} \pm 0.4$ & $5.6^{\mathrm{b}} \pm 0.1$ & $10.7^{\mathrm{c}} \pm 1.3$ & $2.9^{\mathrm{a}} \pm 0.4$ & $3.3^{\mathrm{a}} \pm 0.3$ & $3.3^{\mathrm{a}} \pm 0.6$ & $4.0^{\mathrm{a}} \pm 0.9$ \\
\hline & $\gamma$-butyrolactone & 1613 & 1595 & $\mathrm{~S}, \mathrm{R}, \mathrm{M}$ & $5644.3^{\mathrm{b}} \pm 400.4$ & $3625.8^{\mathrm{a}} \pm 401.9$ & $5561.9^{\mathrm{b}} \pm 997.3$ & $3579.8^{\mathrm{a}} \pm 486.7$ & $3411.7^{\mathrm{a}} \pm 433$ & $2785.5^{\mathrm{a}} \pm 339.5$ & $3252.8^{\mathrm{a}} \pm 552.7$ & $3074.3^{\mathrm{a}} \pm 807.8$ \\
\hline & Methionol & 1709 & 1714 & $\mathrm{~S}, \mathrm{R}, \mathrm{M}$ & $774.9^{\mathrm{a}} \pm 15.4$ & $613.3^{\mathrm{a}} \pm 7.7$ & $804.5^{\mathrm{a}} \pm 217.4$ & $606.2^{\mathrm{a}} \pm 15.7$ & $380.2^{\mathrm{a}} \pm 42.7$ & $324.5^{\mathrm{a}} \pm 97$ & $493.2^{\mathrm{a}} \pm 64.8$ & $381.9^{\mathrm{a}} \pm 201.0$ \\
\hline & $\beta$-damascenone* & 1809 & 1752 & $\mathrm{~S}, \mathrm{R}, \mathrm{M}$ & $6^{\mathrm{a}} \pm 0.3$ & $6.5^{\mathrm{a}, \mathrm{b}} \pm 0.4$ & $7.4^{\mathrm{b}} \pm 0.3$ & $7.3^{\mathrm{b}} \pm 0.7$ & $6.5^{\mathrm{a}} \pm 0.4$ & $7^{\mathrm{a}} \pm 0.4$ & $8 .{ }^{\mathrm{a}} 6 \pm 0.1$ & $7.9^{\mathrm{a}} \pm 2.2$ \\
\hline
\end{tabular}


$616 \uparrow$ Retention index calculated by SPME with an alkane mixture (C5-C30)

$617+$ Retention index reported in the literature from Flavornet database: http://www.webbook.nis.gov/chemistry

$618 \S$ Identification method: S, identification by comparison with standard compounds; RI, identified by retention index; MS, identified by mass spectra (NIST

619 libraries)

620 Different supercripts denote statistical differences $(p<0.05)$ in the values in the same row for each type of wine 
621

622 
624 Table 4. Results from the two-way ANOVA (concentration, judge, concentration x judge) and

625 F-ratios of the sensory terms evaluated by the 10 judges during training in 6 attributes at 2

626 different concentrations.

627

628

\begin{tabular}{llll}
\hline Attributes & Concentration & Judge & Concentration x judge \\
\hline Acidity & $162.00^{* * *}$ & 0.22 & - \\
Banana & $1699.54^{* * *}$ & 1.05 & 1.53 \\
Floral & $1077.5^{* * *}$ & 1.26 & 1.68 \\
Peach & $98.92^{* * *}$ & 0.20 & 1.98 \\
Strawberry & $2366.46^{* * *}$ & $2.78^{*}$ & $9.5^{* * *}$ \\
Yeast & $116.55^{* * *}$ & 1.02 & 2.28 \\
\hline
\end{tabular}

629

$*$ and $* * *$ denote significance at $p<0.05$ and $p<0.001$ respectively

630

631 
632 Table 5. Results obtained on the descriptive analysis by the panel of judges $(n=10)$ of the 6 633 sensory attributes evaluated in the control (Cont-W) and GSH-IDY wines (GSH-IDY-W) after 6349 months of aging

\begin{tabular}{lcccc}
\hline & & & \multicolumn{2}{c}{ Mean } \\
Attributes & F-ratio & p-value & Cont-W-9m & GSH-IDY-W-9m \\
\hline Acidity & 0.00 & 0.9944 & 7.72 & 7.71 \\
Banana & $\mathbf{3 . 2 3}$ & $\mathbf{0 . 0 9 1 1}$ & $\mathbf{4 . 5 1}$ & $\mathbf{7 . 1 6}$ \\
Floral & 0.17 & 0.6875 & 7.59 & 8.24 \\
Peach & $\mathbf{4 . 0 7}$ & $\mathbf{0 . 0 5 8 9}$ & $\mathbf{7 . 6 5}$ & $\mathbf{4 . 8 1}$ \\
Strawberry & $\mathbf{8 . 1 3}$ & $\mathbf{0 . 0 1 1 6}$ & $\mathbf{4 . 0 2}$ & $\mathbf{7 . 8 7}$ \\
Yeast & $\mathbf{1 1 . 4 6}$ & $\mathbf{0 . 0 0 3 8}$ & $\mathbf{4 . 3 1}$ & $\mathbf{1 . 9 1}$ \\
\hline
\end{tabular}

637

638 Judges 1 and 10 not consistent with the whole panel were excluded from data analysis 639 of strawberry and banana attributes. Attributes in bold were significantly different 640 between wines.

641 


\section{Figure Captions}

643

644 Figure 1. Dendrogram resulting from the application of cluster analysis to the data 645 corresponding to the concentration of volatile compounds determined in the wines of

646 different aging time (1, 2, 3 and 9 months) made with or without the addition of a 647 glutathione enriched IDY preparation (G-IDY-W and Cont-W, respectively)

648

649 Figure 2. Aroma profiles of Grenache rosé wines in the control wine (Cont-W) and in 650 the wine supplemented with a glutathione enriched IDY preparation (GSH-IDY-W) 651

652 